\title{
Obesity Effect on Children Hip and Knee Range of Motion
}

\author{
Silvia Maria Amado João1, Maira Nomura Nishizaki', Cynthia Hitomi Yamamoto1, \\ Vera Lúcia Perino Barbosa², Juliana Ferreira Sauer ${ }^{{ }^{*}}$ \\ ${ }^{1}$ Physical Therapy Course of the School of Medicine, Department of Physical Therapy, \\ Speech and Occupational Therapy, University of São Paulo, São Paulo, Brazil \\ ${ }^{2}$ Movere Institute for Obese Children, São Paulo, Brazil \\ Email: ${ }^{*}$ jujusauer@yahoo.com.br
}

Received 13 February 2014; revised 12 March 2014; accepted 11 April 2014

Copyright (C) 2014 by authors and Scientific Research Publishing Inc.

This work is licensed under the Creative Commons Attribution International License (CC BY). http://creativecommons.org/licenses/by/4.0/

(c) (i) Open Access

\begin{abstract}
The aim of this study was to characterize the obesity effect on children knee and hip joint range of motion. A randomized controlled trial was performed with goniometry evaluation for hip flexion, extension, abduction, adduction, external and internal rotation, and knee flexion in fifty male children (20 obese and 30 non obese), with age ranging from 6 to 12 years old. The obesity effect was found to be non-uniform across the joint range of motion. In the obesity group, a statistically significant reduction in the range of motion of hip flexion and adduction, and knee flexion was observed; and also an increase in external rotation in the hip was observed. Conclusion: Obese and overweight children present alterations in hip and knee joints mobility when compared to eutrophic children. The obesity/overweight associated with factors previously described in the literature, such as joint overload, postural deviation and sedentariness may influence the musculoskeletal development and, consequently, the motor function.
\end{abstract}

\section{Keywords}

Obesity, Children, Body Joint Motion, Range of Motion

\section{Introduction}

Obesity is defined as the excessive and generalized accumulation of fat in the subcutaneous tissue and in other tissues, and it may cause health damage [1]. Overweight is defined, according to the Obesity Latin-American Consensus, as a pre-obesity stage [2].

\footnotetext{
${ }^{*}$ Corresponding author.
} 
Infantile obesity has become an epidemic proportion problem in North America and worldwide [3]. In Brazil, $16.7 \%$ of the young population from 10 to 19 years old present excess of weight, and about $2 \%$ of the Brazilian adolescents were diagnosed as obese, according to the Brazilian Geography and Statistic Institute [4]. In the United States, the prevalence of overweight and obesity among children and adolescents from 6 to 19 years old is $31.5 \%$ [5]. In Australia, child and adolescent obese population range from $19 \%$ to 23\% [6] [7]. Another research in Australia shows that the overweight and obesity prevalence doubled among youths from 7 to 15 years old [8].

The obesity cause many health complications such as hypertension, cardiovascular diseases, diabetes mellitus, and mobility and joint injuries [9], like osteoarthritis [10]. During childhood, the main risks are respiratory problems, triglyceride and cholesterol increase, and orthopedic disturbs [1].

Obesity can reduce joint range of motion because the amount of adipose tissue can interpose and obstruct inter-segmental rotations [11]. Very few authors have shown the articular range of motion in obese adults and the results have shown a reduced articular range of motion for superior and inferior limbs and spine [11]-[13].

There is no information about obese children range of motion and such understanding will elucidate the physical capabilities and facilitate the development of systems that comfortably accommodate these individuals, as well as the development of products, workplaces and allowing a reference for rehabilitation process.

The normal articular range of motion is important because it has to provide balance between mobility and stability. Both articular limitation and mobility excess can increase the vulnerability to distensions [14]. The reduction of range of motion decreases the articular movement and compromises the appropriate muscle recruitment and consequently, the balance and the gait [15].

Among the orthopedic disturbs spine and lower limbs postural alterations are the most common during childhood and adolescence, when the musculoskeletal system is under development, which makes the human body more susceptible to deformations and mobility alterations [16].

The clinical measurement of joint range of motion is an important issue in a musculoskeletal examination that allows the planning of a treatment program and the evaluation of a therapeutic intervention [17] [18]. When facing the health issue that is obesity and the relative scarceness of available information about joint mobility in children, the need to focus on the mechanical consequences of obesity is undeniable.

Very few studies have examined the joint range of motion of obese people [12]. To address this, the goal of this study was to assess the hip and knee articular ranges of motion of obese children, and to perform a comparison between these obese children and a control group of eutrophic children.

\section{Methods}

The study participants were randomly recruited. Thirty health children of a public state school of São Paulo were allocated in non-obese group and 20 obese or overweight children from the Movere Institute for Community Actions and from the Pediatrics Ambulatory of the University Hospital of the University of São Paulo were allocated in obese group. Male children from six to 12 years old composed both groups.

Children with joint hypermobility [19], metabolic diseases [20], musculoskeletal diseases [21], neurological diseases [22], lower limbs recent injury, and children who practice institutionalized sport or physical exercise [23] [24] in addition to the physical activity proposed by the school in a frequency greater than twice a week and/or greater than 3 hours per week were excluded from the sample.

Physical eligibility of study participants was assessed by a questionnaire containing all the exclusion criteria, which was developed by a licensed physical therapist.

Each child underwent a hypermobility test proposed by Beighton [25], and all the children that scored 4 ore more, were excluded from the research.

All the subjects and their responsible were aware of the experimental procedures and signed an Informed Consent Form. The Ethics Committee approved this research for Analysis of Research Projects of the Clinical Administration of the Hospital of the Clinics of the Medicine College of the University of São Paulo, and by the Education and Research Committee of the University Hospital of the University of São Paulo.

Initially, body height and weight were measured to calculate the body mass index (BMI). The BMI was calculated dividing the weight (in kilograms) by the square of the height (in meters) [1] [26]. Specific BMI were considered for each age. The BMI of obese or overweight children had to be above the 85 percentage of the BMI by age distribution graphic of the National Center of Health Statistics (NCHS) [27], while for the group of eu- 
trophic children, the values had to be under the 85 percentage, represented by the cut points shown in the Table 1. The participants body masses and heights were measured at the site of data collection.

After calculating the BMI, hip flexion, extension, abduction, adduction, external rotation, and internal rotation range of motion and knee flexion range of motion were measured. The articular range of motion was assessed by goniometric measurement in bilateral passive movement, performed according to Palmer and Epler [28]. The passive movement was performed until the subject refers discomfort or when compensatory movements occurred [29].

Two assessors performed the evaluations and the measurements were correlated. Intra-assessor Reliability: The assessor number 1 performed the measurements of the 50 subjects twice, which were compared among them. Inter-assessor Reliability: The assessor number 2 performed the measurements of the 50 subjects once, which were compared with the measurements of the assessor number1 to obtain inter-assessor reliability [30]. The time interval among the three measures performed by the assessors was at least one week, and at last one month.

The reliability was measured by the intraclass correlation index (ICI). In the ICI, the values ranged from 0 to 1.0 [31], with cut points above 0.75 that indicates good reliability, and under 0.75 indicating poor or moderate reliability [32].

The following instruments were used: $\mathrm{Carci}^{\circledR}$ goniometer, Pimaco ${ }^{\circledR}$ spherical paper adhesives, metrical tape, Plena ${ }^{\circledR}$ digital balance, and a portable cot.

The mean and standard deviation were calculated for each movement of the obese children group and eutrophic children group (Microsoft Excel). The intra and inter-assessor reliability was obtained by the intraclass correlation index (SPSS for Windows).

To verify if there was a statistically significant difference between the body sides of the same group of subjects (dominance), the t-Test was used for dependent samples when the distribution was normal, and the Wilcoxon Test was used when the distribution was non-normal (Statistica).

To verify if there was statistically significant difference between the group of obese children and the group of eutrophic children, t-Test was used for the independent samples when the distribution was normal, and the Mann-Whitney Test was used when the distribution was non-normal (Statistica). The level of significance was established in 0.05 .

\section{Results}

The characterization of age, weight, height and BMI of the subjects is in Table 2. Obese children showed a mean age of nine years old and a mean BMI of $26 \mathrm{~kg} / \mathrm{cm}^{2}$.

In Table 3 are presented the intra and inter-assessors correlation indexes obtained during assessment of the children of non-obese and obese group, respectively. The reliability of the measures intra and inter the two assessors was good, with indexes above 0.75 .

Both obese and non-obese children did not present statistically significant differences between right and left sides range of motion. The hip flexion, adduction, external rotation and knee flexion presented statistically significant difference between obese children and the control group.

\begin{tabular}{|ccc|}
\hline Table 1. Ages and BMI cut points & 1, 20, 21 \\
\hline Age (Years) & Non-Obese Group* & Obese Group* \\
\hline 6 & $\leq 17$ & $>17$ \\
7 & $\leq 17.4$ & $>17.4$ \\
8 & $\leq 17.9$ & $>17.9$ \\
9 & $\leq 18.6$ & $>18.6$ \\
10 & $\leq 19.4$ & $>19.4$ \\
11 & $\leq 20.1$ & $>20.1$ \\
12 & $\leq 21$ & $>21$ \\
\hline
\end{tabular}

*Specific BMI considered for each age. 
Table 2. Sample characterization (age, body mass, height and BMI).

\begin{tabular}{ccccc}
\hline & \multicolumn{2}{c}{ Non-Obese Group $(\mathrm{n}=30)$} & \multicolumn{2}{c}{ Obese Group $(\mathrm{n}=20)$} \\
\cline { 2 - 5 } & Mean (SD) & Interval & Mean (SD) & Interval \\
\hline Age (years) & $8.40(1.65)$ & $6-12$ & $56.70(1.92)$ & $6-12$ \\
Weight $(\mathrm{kg})$ & $26.97(6.48)$ & $17.4-51.9$ & $1.45(0.09)$ & $35.9-82.7$ \\
Height (m) & $1.30(0.10)$ & $1.11-1.59$ & $26.78(4.97)$ & $1.29-1.61$ \\
BMI $\left(\mathrm{kg} / \mathrm{cm}^{2}\right)$ & $15.60(1.61)$ & $13.22-20.53$ & & $19.40-35.83$ \\
\hline
\end{tabular}

BMI: body mass index.

Table 3. Reliability of the measures intra and inter-assessor.

\begin{tabular}{ccccc}
\hline & \multicolumn{2}{c}{ Intra-Assessor } & \multicolumn{2}{c}{ Inter-Assessor } \\
\cline { 2 - 5 } & Right & Left & Right & Left \\
\hline Movement & NOG/OG & NOG/OG & NOG/OG & NOG/OG \\
Hip flexion & $0.954 / 0.986$ & $0.944 / 0.879$ & $0.869 / 0.978$ & $0.930 / 0.965$ \\
Hip extension & $0.968 / 0.991$ & $0.968 / 0.994$ & $0.965 / 0.987$ & $0.982 / 0.975$ \\
Hip abduction & $0.931 / 0.928$ & $0.825 / 0.900$ & $0.903 / 0.977$ & $0.762 / 0.885$ \\
Hip adduction & $0.830 / 0.988$ & $0.916 / 0.964$ & $0.927 / 0.951$ & $0.894 / 0.966$ \\
Hip Internal rotation & $0.926 / 0.959$ & $0.910 / 0.966$ & $0.880 / 0.883$ & $0.753 / 0.951$ \\
Hip external rotation & $0.946 / 0.984$ & $0.946 / 0.987$ & $0.850 / 0.991$ & $0.820 / 0.977$ \\
Knee flexion & $0.952 / 0.987$ & $0.963 / 0.993$ & $0.939 / 0.952$ & $0.965 / 0.987$ \\
\hline
\end{tabular}

NOG: non-obese group/OG: obese group.

In the Table 4 are presented the passive hip and knee range of motion and the standard deviation of obese children and eutrophic group. The measures of the first assessment of the assessor number one were used randomly, whereas the reliability was considered excellent and, therefore, these measures are representative for the eutrophic and obese children groups. Obese children shown a reduced articular range of motion in hip flexion (p $=0.00)$, hip adduction $(\mathrm{p}=0.00)$ and knee flexion $(\mathrm{p}=0.00)$.

\section{Discussion}

This study investigated the obesity effect on children hip and knee range of motion based on data collected from a sample of 20 obese and 30 non-obese children. Our data show that obese children have significantly reduced range of motion in the hip flexion and adduction and knee flexion movements and increased range of motion in the hip external rotation movement. For the rest of motions, no significant obesity effect was found. The intra and inter-assessor reliability of the goniometric measurement was excellent.

There is no sense about how obesity affects mobility in children. In obese adults, range of motion limitation is present due to the excess of fat tissue that would interpose and mechanically obstruct intersegment rotations at body joints [11]-[13] [33].

Gajdosik and Lusin [34], and Gajdosik et al. [35] demonstrated that even complex movements can be measured in a reliable way, when the procedures of goniometry are appropriately controlled.

The assessment was conducted in a passive way whereas it provides the exact information about the articular surface integrity and about the joint capsule, ligaments and muscles extensibility [36]. The flexibility of a synovial joint is determined by factors such as the shape of articular surfaces, joint capsule and ligaments tension, and soft parts mass [37].

However, to understand the mobility alteration, it is necessary to focus on obese population postural alterations. Alterations such as valgus knee and hip internal rotation are described in the literature [1] [38]. Due to an 
Table 4. Comparison of hip and knee range of motion by groups.

\begin{tabular}{rccc}
\hline Movement & Non-Obese Group $(\mathrm{n}=30)$ & Obese Group $(\mathrm{n}=20)$ & $\mathrm{p}$ \\
\hline Hip flexion & $138.13 \pm 8.48$ & $120.70 \pm 8.04$ & $0.00^{*}$ \\
Hip extension & $15.67 \pm 4.64$ & $17.45 \pm 7.12$ & 0.28 \\
Hip abduction & $44.20 \pm 5.05$ & $44.25 \pm 5.32$ & 0.97 \\
Hip adduction & $13.14 \pm 2.92$ & $10.45 \pm 3.95$ & $0.00^{*}$ \\
Hip internal rotation & $50.23 \pm 7.79$ & $46.85 \pm 6.21$ & 0.11 \\
Hip external rotation & $48.20 \pm 7.17$ & $50.25 \pm 12.75$ & $0.00^{* *}$ \\
Knee flexion & $148.70 \pm 3.69$ & $136.40 \pm 8.00$ & $0.00^{* *}$ \\
\hline
\end{tabular}

*Statistically significant for $\mathrm{p}<0.05$ in $\mathrm{t}$ - test for independent samples, **Statistically significant for $\mathrm{p}<0.05$ in Mann-Whitney test.

increased volume, the thighs would impose a separation of the lower limbs and an increase of the pelvic anteversion leading to an internal rotation of the hips and a hyperpression of the lateral compartments of the knees. As an answer, occur a retard in the development of the lateral compartment and an exaggerated growth of the medial compartment, installing a valgus knee. Serra et al. [38] verified that $50 \%$ of the obese children present pathological valgus knee, with an intramalleolar distance greater than $10 \mathrm{~cm}$.

The hip internal rotation and the valgus knee, with consequent hip adduction, form a situation of joint instability, whereas for a major hip cooptation 3 elementary movements are needed: flexion of about $90^{\circ}$, abduction and external rotation [38] [39]. The sedentariness of obese children can increase this instability, associated to probable muscle strength impairment [40] [41]. According to Ardle et al. [36], the physical activity hypertrophies the ligaments and the conjunctive tissue, resulting in a muscle enlarging and strengthening, improving the proprioception and developing protecting reflex reactions, with consequent increase of the joint stability [7].

The decrease of the muscle activity and strength, and the different muscle positioning can evoke an inappropriate muscle adaptation due to the instable movement. Thus, obese children could present a better range of motion of all instable movements of the hip (extension, internal rotation and adduction). However, only a decrease of the adduction was observed, which is a movement that, during the assessment, was promptly compensated by the pelvis and by the spine, probably a protective mechanism of this instability.

Another aspect to be considered is the action of ligaments located anteriorly in the hip: iliofemoral ligament (IFL), pubofemoral ligament (PFL) and ischiofemoral ligament (ISFL). These ligaments have inverse actions during hip rotational movements; IFL and PFL limit external rotation and ISFL limits internal rotation [28]. The posture in internal rotation of the hip described in the literature [1] [38] [39] impedes the ligaments, that limit the external rotation, to suffer the necessary tension for the increase of its transversal area, thus allowing a greater mobility in this movement. According to Cohen and Cohen [40], the tension exerted on tendon and ligaments creates an amplification of its transversal areas in a way to restore the ideal deformation spot. Despite of this posture in internal rotation of hip also creates a shortening of the involved muscles, these muscles seems not to influence the mobility of external rotation of hip.

The great volume of muscle mass, and abdomen, thighs and legs adipose tissue could limit hip flexion and knee flexion movements. According to Kapandji [39], the passive knee flexion movement is limited by the elastic contact of the muscle masses of the calf and the hip. The thighs areas, specially the backsides, are known to easily deposit fat and it is thought to be the main reason for the obesity associated range of motion reduction for the knee flexions [12].

Aside from excess fat, reduced physical activity might also be a contributor to the observed range of motion limitations observed, as obesity is frequently associated with a lower level of physical activity [18] and physical inactivity can decrease body flexibility [31].

Some limitations of the current study are described here alongside future research directions. The sample size in this study allowed statistical testing and characterization of the obesity effects on male children range of motion, but it was not large enough to generate statistics.

One of the limitations of this research is the fact that the subjects were not separated by race, and the reduced size of the sample. With regard to the race, the joint mobility is greater in individuals with Indian origin, fol- 
lowed by Africans, and, in last, the Caucasians [24]. However, it is difficult to separate the individuals in the Brazilian population whereas the major part of the population is a mixture of races, due to the huge ethnic diversity of Brazil.

Another limitation of the study is the union of obese and overweight children in the same experimental group. In future studies, other obesity categories, such as overweight obese group, should be considered to provide a more complete understanding of the obesity effect. The current study collected only male participant's range of motion data. Further research is needed to characterize the obesity effect on female children range of motion.

\section{Conclusion}

It was concluded that obese and overweight children present hip and knee joint mobility alterations when compared to eutrophic children. The hip flexion and adduction range of motion were decreased, and hip external rotation range of motion was increased. The obesity/overweight factor associated with other factors like joint overload, postural alterations and sedentariness can exert an influence on the musculoskeletal development and, consequently, on the range of motion. Thus, joint mobility alterations are presented as one of the risk factors of possible orthopedic problems.

\section{References}

[1] Fisberg, M. (2004) Atualizações em Obesidade na Infância e Adolescência. $1^{\mathrm{a}}$ ed., Editora Atheneu, São Paulo;.

[2] Perecin, J.C., Benício, N.C.D., Gastaldi, A.C. and Sousa, T.C. (2003) Teste de caminhada de seis minutos em adultos eutróficos e obesos. Revista Brasileira de Fisioterapia, 7, 245-251.

[3] Deckelbaum, R.J. and Williams, C.L. (2001) Childhood Obesity: The Health Issue. Obesity Research, 9, $2395-43 S$. http://dx.doi.org/10.1038/oby.2001.125

[4] Instituto Brasileiro de Geografia e Estatística (IBGE) (2009) Pesquisa de orçamentos familiares 2008-2009. Antropometria e análise do estado nutricional de crianças e adolescentes no Brasil. http://www.ibge.gov.br/home/estatistica/populacao/condicaodevida/pof/2008_2009_encaa/defaulttabpdf.shtm

[5] Hedley, A.A., Ogden, C.L., Johnson, C.L., Carroll, M.D., Curtin, L.R., Flegal, K.M. (2004) Prevalence of Overweight and Obesity Among US Children, Adolescents, and Adults, 1999-2002. JAMA, 291, 2847-2850. http://dx.doi.org/10.1001/jama.291.23.2847

[6] Cameron, A.J., Welborn, T.A., Zimmet, P.Z., Dunstan, D.W., Owen, N., Salmon, J., et al. (2003) Overweight and Obesity in Australia: The 1999-2000. Australian Diabetes, Obesity and Lyfestyle Study (AusDiab). Medical Journal of Australia, 178, 427-432.

[7] Booth, M.L., Wake, M., Armstrong, T., Chey, T., Hesketh, K., Mathur, S. (2001) The Epidemiology of Overweight and Obesity among Australian Children and Adolescents, 1995-97. Australian and New Zealand Journal of Public Health, 25, 162-169. http://dx.doi.org/10.1111/j.1753-6405.2001.tb01840.x

[8] Booth, M.L., Chey, T., Wake, M., Norton, K., Hesketh, K., Dollman, J., et al. (2003) Change in the Prevalence of Overweight and Obesity among Young Australian, 1969-1997. The American Journal of Clinical Nutrition, 77, $29-36$.

[9] Kaodhiar, L., McCowen, K.C. and Blackburn, G.I. (1999) Obesity and Its Comorbid Conditions. Clinical Cornerstone, 2, 17-31. http://dx.doi.org/10.1016/S1098-3597(99)90002-9

[10] Powell, A., Teichtahl, A.J., Wluka, A.E., Circuttini, F.M. (2005) Obesity: A Preventable Risk Factor for Large Joint Osteoarthritis Which May Act through Biomechanical Factors. British Journal of Sports Medicine, 39, 4-5. http://dx.doi.org/10.1136/bjsm.2004.011841

[11] Kendall, F.P., McCreary, E.D. and Provance, P.G. (1993) Muscles: Testing and Function. 4th Edition, Williams \& Wilkins, Baltimore.

[12] Shumway-Cook, A. and Woollacott, M. (1995) Motor Control, Theory and Practical Applications. 1st Edition, Williams \& Wilkins, Baltimore.

[13] Hills, A.P., Henning, E.M., Byrne, N.M. and Steele, J.R. (2002) The Biomechanics of Adiposity-Structural and Functional Limitations of Obesity and Implications for Movement. Obesity Reviews, 3, 35-43. http://dx.doi.org/10.1046/j.1467-789x.2002.00054.X

[14] Adib, N., Davies, K., Grahame, R., Woo, P. and Murray, K.J. (2005) Joint Hypermobility Syndrome in Childhood. A Not So Benign Multisystem Disorder? Rheumatology, 44, 744-750. http://dx.doi.org/10.1093/rheumatology/keh557

[15] Komatsu, W.R., Gabbay, M.A.L., Dib, S.A. (2004) Early Subclianical Limited Axial and Large Joint Flexibility in Type 1 Diabetes Mellitus Adolescents. Journal of Diabetes and its Complications,18, 352-355. http://dx.doi.org/10.1016/s1056-8727(03)00117-x 
[16] Steultjens, M.P., Dekker, J., van Baar, M.E., Oostendorp, R.A. and Bijlsma, J.W. (2000) Range of Joint Motion and Disability in Patients with Osteoarthritis of the Knee or Hip. Rheumatology, 39, 955-961. http://dx.doi.org/10.1093/rheumatology/39.9.955

[17] Kuno, H., Suzuki, N., Akataki, K., Mita, K., et al. (1998) Geometrical Analysis of Hip and Knee Joint Mobility in Cerebral Palsied Children. Gait Posture, 8, 110-116. http://dx.doi.org/10.1016/S0966-6362(98)00019-8

[18] Rose Jr., D. (2002) Esporte e atividade física na infância e na adolescência: uma abordagem multidisciplinar. $1^{\mathrm{a}}$ ed., Artmed Editora, Porto Alegre.

[19] Foss, M.L. and Keteyian, S.J. (1998) Fox’s Physiological Basis for Exercise and Sport. 6th Edition, McGraw-Hill, Boston.

[20] Beighton, P., Solomon, L. and Soskolne, C.L. (1973) Articular Mobility in an African Population. Annals of the Rheumatic Diseases, 32, 413-418. http://dx.doi.org/10.1136/ard.32.5.413

[21] Dalton, S. and Watts, S.O. (2002) Defining Childhood Obesity: Revised 2000 Growth Charts, Body Mass Index, and Public Perceptions. Topics in Clinical Nutrition, 17, 7-20. http://dx.doi.org/10.1097/00008486-200212000-00003

[22] Kuczmarski, R.J., Ogden, C.L., Grummer-Strawn, L.M., Flegal, K.M., Guo, S.S., Wei, R., Mei, Z., Curtin, L.R., Roche, A.F. and Johnson, C.L. (2000) CDC Growth Charts: United States. Advance Data, 314, 1-27.

[23] Palmer, M.L. and Epler, M.E. (1998) Fundamentals of Musculoskeletal Assessment Techniques. 2nd Edition, LippincottRaven Publishers, Philadelphia.

[24] Aalto, T.J., Airaksinen, O., Harkonen, T.M. and Arokoski, J.P. (2005) Effect of Passive Stretch on Reproducibility of Hip Range of Motion Measurements. Archives of Physical Medicine and Rehabilitation, 86, 549-557. http://dx.doi.org/10.1016/j.apmr.2004.04.041

[25] Gunal, I., Kose, N., Erdogan, O., Gokturk, E. and Seber, S. (1996) Normal Range of Motion of the Joints of the Upper Extremity in Male Subjects, with Special Reference to Side. Journal of Bone \& Joint Surgery, 78, 1401-1404.

[26] Portney, L. and Watkins, M. (2000) Foundations of Clinical Research: Applications to Practice. 2nd Edition, Prentice Hall Health, New Jersey.

[27] Gadotti, I.C., Vieira, E.R. and Magee, D.J. (2006) Importance and Clarification of Measurement Properties in Rehabilitation. Brazilian Journal of Physical Therapy, 10, 137-146. http://dx.doi.org/10.1590/S1413-35552006000200002

[28] Gajdosik, R.L. and Lusin, G.F. (1983) Hamstring Muscle Tightness: Reliability of an Active-Knee-Extension Test. Physical Therapy, 63, 1085-1088.

[29] Gajdosik, R.L., Simpson, R., Smith, R. and Don Tigny, R.L. (1985) Pelvic Tilt: Intratester Reliability of Measuring the Standing Position and Range of Motion. Physical Therapy, 65, 169-174.

[30] Norkin, C.C. and White, D.J. (1995) Measurement of Joint Motion: A Guide to Goniometry. 2nd Edition, F.A. Davis Co., Philadelphia.

[31] Watkins, J. (1999) Structure and Function of the Musculoskeletal System. 1st Edition, Human Kinetics Publishers, Champaign.

[32] Serra, B.B., Rioja, A.Q., Buforn, M.A., Orgado, J.M., Hernández, M.E., Perez, F.J. and Picarzo, L. (2003) Presencia de genu valgum en obesos: Causa o efecto. Anales de Pediatría, 58, 232-235. http://dx.doi.org/10.1016/S1695-4033(03)78043-6

[33] Norkin, C.C. and Levangie, P.K. (2005) Joint Structure and Function: A Comprehensive Analysis. 4th Edition, F.A. Davis, Philadelphia.

[34] Sorensen, T.I.A. (2000) The Changing Lifestyle in the World: Body Weight and What Else? Diabetes Care, 23, B1-B4.

[35] Andersen, R.E., Crespo, C.J., Barlett, S.J., Cheskin, L.J. and Pratt, M. (1998) Relationship of Physical Activity and Television Watching with Body Weight Level of Fatness among Children. JAMA, 279, 938-942. http://dx.doi.org/10.1001/jama.279.12.938

[36] Ardle, W.D., Katch, F.I. and Katch, V.L. (2001) Exercise Physiology: Energy, Nutrition, and Human Performance. 5th Edition, Lippincott Williams \& Wilkins, Philadelphia.

[37] Brown, G.A., Tan, J.L. and Kirkley, A. (2000) The Lax Shoulder in Females. Issues, Answers, but Many More Questions. Clinical Orthopaedics and Related Research, 372, 110-122. http://dx.doi.org/10.1097/00003086-200003000-00013

[38] Penha, P.J., João, S.M., Casarotto, R.A., Amino, C.J. and Penteado, D.C. (2005) Postural Assessment of Girls between 7 and 10 Years of Age. Clinics, 60, 9-16. http://dx.doi.org/10.1590/S1807-59322005000100004

[39] Kapanji, I.A. (1988) The Physiology of the Joints: Lower Limb, Vol. 2. 5th Edition, Elsevier, Amsterdam.

[40] Cohen, L.A. and Cohen, M.H. (1956) Arthrokinetic Reflex of the Knee. American Journal of Physiology —Legacy Content, 184, 433-437. 
[41] Klemp, P., Williams, S.M. and Stansfield, A. (2002) Articular Mobility in Maori and European New Zealanders. Rheumatology, 41, 554-557. http://dx.doi.org/10.1093/rheumatology/41.5.554

\section{Abbreviations}

Body mass index (BMI)

National Center of Health Statistics (NCHS)

Intraclass correlation index (ICI)

Iliofemoral ligament (IFL)

Pubofemoral ligament (PFL)

Ischiofemoral ligament (ISFL).

Non-obese group (NOG)

Obese group (OG) 